\title{
Health System Bottlenecks in Achieving Maternal and Child Health-Related Millennium Development Goals: Major Findings from District Level in Bangladesh
}

\author{
Anwar Islam ${ }^{1}$ and Tuhin Biswas ${ }^{2}$ \\ 1. School of Health Policy and Management, York University, Toronto M3J1P3, Canada \\ 2. Department of Public Health, North South University, Basundhara, Dhaka 1229, Bangladesh
}

\begin{abstract}
The overall purpose of the study was to identify key health system bottlenecks at the district level in achieving the MNCH (maternal neonatal and child health) related Millennium Development Goals and to cost out the marginal financial resources required to address them in three districts of Bangladesh. The goal was to assist the government in identifying cost-effective interventions in addressing some of the critical health system bottlenecks with particular focus on health equity and the needs of the disadvantaged population. The study, conducted exclusively on the public sector health service providers at the district level, adopted a mixed method approach. Using the Tanahashi model, the quantitative part attempted to identify the extent of the health system bottlenecks on human resources, accessibility, logistics, financing and utilization of services at the selected districts. The qualitative part dealt with the FGDs (focus group discussions) and in-depth interviews conducted on the government health personnel in order to better understand and analyze the bottlenecks. The World Bank developed MBB (marginal budgeting for bottlenecks) tool that was used to estimate the marginal cost of addressing these bottlenecks. The study identified human resource constraints-inadequate numbers, poor expertise, grossly uneven geographical distribution and lack of awareness as the most critical bottleneck affecting health systems at the district level. Inequity in the availability of accessibility to health care services was pronounced and manifested in different dimensions - geographical setup, socioeconomic status and gender. The marginal costs of addressing these bottlenecks are significant in the context of the total health expenditure in Bangladesh. Existing human resource policy needs to be revised to improve the overall quality of services. Allocation of additional resources and interventions should be district specific. Awareness programs need to be strengthened by using effective behavioral change and communication strategies. Moreover, special effort is required to address the equity issue.
\end{abstract}

Key words: Health system, bottlenecks, millennium development goals.

\section{Introduction}

Over the last few years, significant progress has been made in health and development across the developing world. The infant mortality rate declined from over 150 per 1,000 live births in 1960s to around 90 by 2000 . Similarly, the MMR (maternal mortality ratio) also declined albeit less dramatically; MMR still stands around 350 to 400 per 100,000 live births in many developing countries including Bangladesh [1]. New

Corresponding author: Anwar Islam, Ph.D., adjunct professor, research fields: health systems, health economics/health care financing, health policy and planning, health sector reform and chronic diseases. E-mail: aislam@yorku.ca; anwarhill@yahoo.com. tools and approaches are being developed and used to sustain, consolidate and further advance these gains. A number of broad changes is at the heart of these new approaches - the emergence of health as a fundamental human right; the paradigm shift from "providing treatment and services" to "creating health"; the renewed emphasis on health system and a systems approach; the critical value placed on capacity building in management/administration; rededication to the principle of community-based primary health care on the basis of an evidence-based "essential package" of services and the increased use of the mass media to educate and raise awareness of communities; families 
and individuals on the significance of such issues as lifestyle, behavior, food habits, occupation, consumption pattern and the environment on health and well-being. Nevertheless, important challenges remain. As a result, there is increased emphasis on the need for greater efforts to sustain the gains made and achieve the health-related MDGs (Millennium Development Goals). Globally the lack of appropriately trained adequate number of HRH (human resources for health) has been identified as one of the most critical challenges faced by developing countries in achieving the MDGs. At the same time, several studies also identified the lack of management expertise of the key public sector health managers as a critical stumbling block in this regard. There is a lack of expertise in areas such as health systems management, public health, health care financing, and program monitoring and evaluation, especially in relation to services targeting women and children.

\subsection{Quality of Public Sector Health Services}

Moreover, it is strongly felt that the quality of service delivery in the overall public health sector in the country still remains poor. Despite the encouraging trends for infant and child mortality rates, the achievement of MDG 4 is far from guaranteed [2]. The progress in preventing neonatal deaths (deaths in the first month after birth) has been slow. Child health and survival are closely related to the health and survival of mothers throughout their lifecycle. While maternal mortality is difficult to measure and track in Bangladesh, experts agree that maternal deaths are unacceptably common. National survey of maternal mortality conducted in 2001 by the Ministry of Health and Family Welfare with funding from USAID (United States Agency for International Development) found a maternal mortality ratio of 320 per 100,000 live births [3]. Bangladesh is one of only six countries that are making good progress toward the MDG for reducing child mortality but are not making substantial progress toward the MDG for maternal mortality. In 2009, the
Bill and Melinda Gates Foundation and AusAID (Australian Agency for International Development) initiated funding for the development of $\mathrm{MNCH}$ (maternal, newborn and child health) investment cases in Asia (India, Nepal, Indonesia, Philippines and Papua New Guinea) [4]. The goal of this initiative is to build the national and sub-national level evidence required to identify the main health system constraints and bottlenecks hampering the scaling-up of the "best buy range of interventions" required to achieve equitable progress on MDGs 4 and 5, and estimate the additional funding required to effectively addressing these constraints and bottlenecks.

\subsection{District Investment Case Analysis: Its Goal}

DICA (district investment case analysis) provides an opportunity for the government and its development partners to strengthen fragile health systems by highlighting the urgent need to accelerate progress towards achieving health related MDGs (1, 4, 5, 6 and $7)$, leverage resources from the government and its development partners to adequately invest in $\mathrm{MNCH}$ in order to achieve tangible and sustainable results against the MDGs. This paper, based on the DICA analysis, identifies and describes the acute problems in the area of $\mathrm{MNCH}$ at the district level and recommends practical evidence-informed strategies and steps for tackling them by providing detailed cost.

\section{Methodology}

The first step in the DICA study was to chalk out the current situation of the three selected districts in terms of their demographic and epidemiological context, health systems structure, health policies, and current health intervention coverage, based on published datasets and expert inputs. The second step was to explore and identify existing high impact interventions. This step was initiated through a three day long workshop under the auspices of the Ministry of Health and Family Welfare. The interventions were classified under three service delivery modes: (1) 

Goals: Major Findings from District Level in Bangladesh

family oriented community based services; (2) population oriented schedulable services; (3) individual oriented clinical services. The third step was to identify health systems bottlenecks.

\subsection{Bottleneck Analysis: The Tanahashi Model}

The bottleneck analysis is a step-wise analytical approach that assessed six coverage determinants against each of the interventions. The basic structure of the six determinants was based on Tanahashi Model. The interventions within each sub-package are generally affected by the same health systems constraints. For example, tracer on early breast feeding and complementary feeding both are delivered through population oriented services in all districts. Therefore, challenges and bottlenecks in delivering these two interventions are likely to be quite similar. On the other hand, a single intervention was selected from each sub-package and reviewed in terms of identified health systems "bottlenecks" under section three.

\subsection{Qualitative Part: Focus Groups Discussions and Interviews}

The qualitative part dealt with the FGDs (focus group discussions) and in-depth interviews conducted on the government health personnel in order to better understand and analyze the bottlenecks. The World Bank developed MBB (marginal budgeting for bottlenecks) tool that was used to estimate the marginal cost of addressing these bottlenecks.

\section{Results}

The district investment case analysis, conducted in the three districts (Bardarban, Jamalpur and Narail) in diverse areas of Bangladesh, identified numerous health system bottlenecks in achieving the health-related MDGs. Of the three, Bandarban lying in the hilly southern edge of Bangladesh is the smallest district with a population of a little over 340,000. Part of the Chittagong Hill Tracts, Bandarban contains four of the highest peaks in the country. It is also the most sparsely populated district with a population density of about 65 per square kilometer compared to that of 1,126 per square kilometer for Bangladesh as a whole. The Bandarban district is largely populated by a number of small ethnic communities (with different language and religion) than the rest of the population of Bangladesh. For example, while $88 \%$ of the population in Bangladesh is Muslims, in Bandarban they constitute only about $48 \%$ of the total. $38 \%$ of the population of Bandarban are Buddhists, $7.3 \%$ are Christians, and 3.5\% are Hindus.

The Jamalpur district located about 1,000 miles east of the capital city of Dhaka, has a population of more than 2.4 million. Narail, with a population of almost 760,000 , is in a deltaic region of Bangladesh. However, the population density of these two districts-Jamalpur and Narail-is 1,227 and 767 per square kilometer, respectively (Appendix 1 presents a map of Bangladesh showing the location of the three districts under study).

\subsection{Selected Districts: Demographic and Epidemiological Characteristics}

Table 1 summarizes the socio demographic and epidemiological characteristics of the three districts. It is clear that in two of the three districts-Bandarban and Narail — the sex ratio demonstrates a preference for the male child so common in much of South Asia. In Bandarban males constitute $53.3 \%$ of the population; while in Narail $54.2 \%$ of the population are males. Only in Jamalpur the sex ratio (50.5\% males and 49.4\% females) reflects the universal trend. The average literacy rate is a little higher (more than 39\%) in Bandarban and Jamalpur than in Narail (35.6\%). In all the three districts agriculture is the mainstay of life with more than $40 \%$ of the population being engaged in this sector. The rate is the highest in Narail (47.5\%) and the lowest in Bandarban (43\%). At the same time, a substantial number of people in all the three districts work as agricultural labor (working on the farms owned 
Table 1 Socio-demographic characteristics of the districts.

\begin{tabular}{llll}
\hline Variable & Bandarban & Jamalpur & Narail \\
District population & 340,701 & $2,493,916$ & 759,581 \\
\hline Sex & & & \\
\hline Male & $53.3 \%$ & $50.5 \%$ & $54.2 \%$ \\
Female & $46.6 \%$ & $49.4 \%$ & $45.7 \%$ \\
Average literacy rate & $39.5 \%$ & $39 \%$ & $35.6 \%$ \\
\hline Main occupations & & & $47.5 \%$ \\
\hline Agriculture & $43.0 \%$ & $44.0 \%$ & $2.0 \%$ \\
Fishing & & $1.2 \%$ & $18.0 \%$ \\
Forestry & $4.1 \%$ & & $2.4 \%$ \\
Agricultural laborer & $18.7 \%$ & $24.6 \%$ & $1.31 \%$ \\
Wage laborer & $7.0 \%$ & $2.8 \%$ & $10.9 \%$ \\
Industry & & & $7.8 \%$ \\
Commerce & $7.3 \%$ & $10.6 \%$ & $2.6 \%$ \\
Business & & & $7.2 \%$ \\
Service & $8.5 \%$ & $1.3 \%$ & \\
Transport & & $10.4 \%$ & \\
Others & $11.1 \%$ & & \\
\hline
\end{tabular}

by others). Almost a quarter of the population (24.6\%) in Jamalpur works as agricultural laborers. The rates are $18.7 \%$ and $18 \%$ in Bandarban and Narail districts respectively. It is interesting to note that while forestry as a "work area" is confined in Bandarban district only, "business" as a profession is confined to only Narail district. These occupational dissimilarities to a large extent reflect the geographical characteristics of these districts. Similarly "working in the transport sector" was an option in only two districts-Jamalpur and Narail. Being located in a hilly remote region, Bandarban never developed a transport sector.

\subsection{Structural Set-up of the Health System in the Selected Districts}

Table 2 presents the existing structural set-up of the health system in the three selected districts. Community clinics and the Upazila health complexes are the fundamental building blocks of the primary health care system. While the community clinics serve as the lowest village level primary health care outposts, the UHC (Upazila health complexes) provide a range of services having various types of health professionals including physicians and nurses. Table 2 presents a snapshot of the structural setup of the health system in these three districts. Although none of the districts have any tertiary level health facility, other types of health care centers are present in all of them. However, there are substantial disparities among the districts in this regard. For example, Jamalpur has 244 community clinics-1 for roughly every 10,000 population. On the other hand, Bandarban has 29 community clinics or 1 per 11,748 people. This disparity becomes more serious when the hilly terrain and the sparsely populated nature of the Bandarban district are taken into consideration. The Narail district, on the other hand, has 68 community clinics or 1 per 11,170 population. It should be noted that the government has a policy of establishing one community clinic for every 6,000 population covering the entire rural Bangladesh. However, it is yet to be fully implemented [5]. People in Bandarban, Jamalpur and Narail districts are still waiting to get adequate number of this most important element of the primary health care system. Across the three districts, there is a dearth of another important health care facility-MCWC (maternal and child welfare centres). Jamalpur with a population of over 2.4 million has only two MCWCs, while Bandarban 
and Narail each has only one MCWC. As Table 2 indicates, Bandarban also does not have any mission hospital or any clinic in the private sector. Such lack of health facilities is reflected in the bottlenecks identified by the professionals in these districts.

\subsection{Drug Supply at the District Level}

Supply of drugs at the district health care facilities is regulated centrally from the DDS (directorate of drug supplies). There are separate drug stores for health and family planning services at the district level. The private sectors also provide a good flow of supply of drugs like oxytocin, zinc, antibiotics in Jamalpur and Narail districts but not in Bandarban. Due to the geographical context (hill area) the drug supply chain is very much challenged in Bandarban district compared to Jamalpur and Narail.

Fig. 1 presents some common health-related indicators and practices in the three districts. Only in relation to a few health-related indicators, the districts seem to differ substantially. For example, while improved sanitation is available in only about $10 \%$ of the households in Bandarban and Jamalpur, almost $40 \%$ of the households in Narail have improved sanitation. On the other hand, while almost $55 \%$ of people in Bandarban practice hand washing, less than $30 \%$ of people do so in either Jamalpur or Narail. Exclusive breastfeeding, on the other hand, is extremely low in all the three districts (less than 40\%) and especially in Narail (only 34\%). Similarly, the presence of skilled birth attendant at the time of delivery is precariously low in all the three districts (less than 15\%) and notoriously in Narail (5\%). Not surprisingly, less than $50 \%$ of pregnant women in these districts use antenatal care services (for at least once visit during the pregnancy). Contraceptive prevalence rate (modern as well as traditional methods) is also low in all the three districts (about 55\% in Jamalpur and less than $45 \%$ in Bandarban and Narail). Use of modern contraceptive methods is extremely low hovering around $15 \%$ in these districts. On the other hand, while a little more than $60 \%$ of the people in Narail demonstrated knowledge (the nature of the disease and its transmission) on HIV/AIDS (human immunodeficiency virus infection/acquired immunodeficiency syndrome), only about $30 \%$ of the people in Bandarban did so.

Table 2 Structural setup of health systems in the three districts.

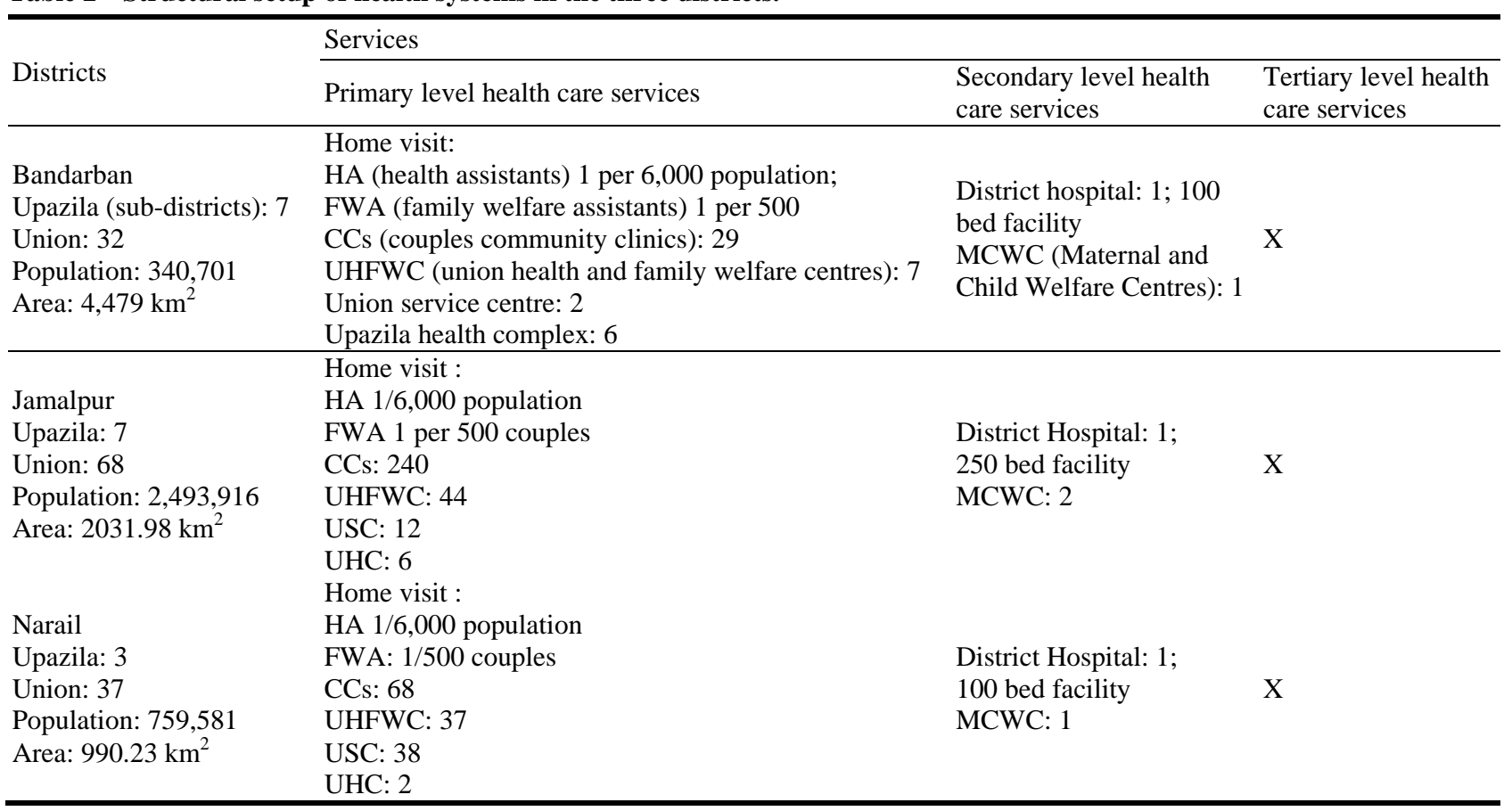




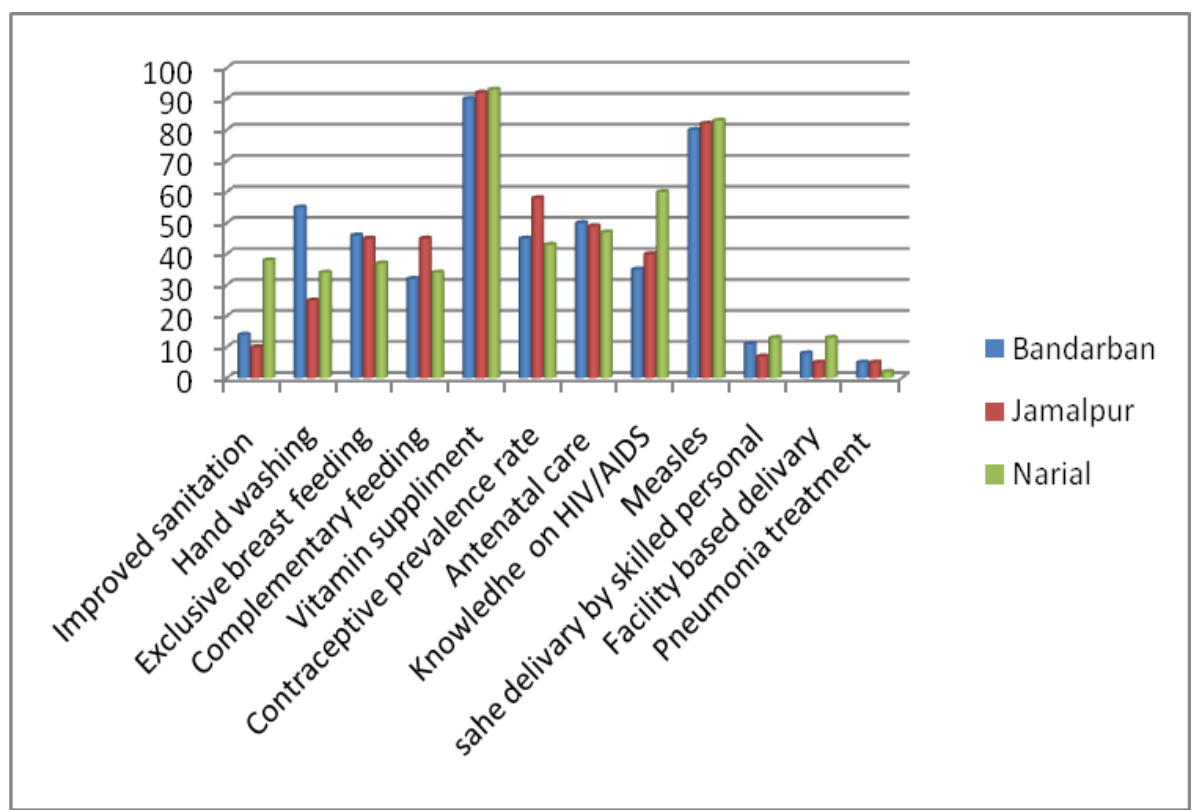

Fig. 1 Selected health-related indicators and practices in the three districts.

Source: MICS (Multiple indicator cluster survey), Bangladesh, 2006.

Table 3 Selected social and health indicators in the districts.

\begin{tabular}{llll}
\hline Variables & Bandorban & Jamalpur & Narail \\
\hline IMR (infant mortality rate) & 23.6 per 1,000 live births & 70 per 1,000 live births & 10.2 per 1,000 live births \\
Under 5 mortality & 54 per 1,000 live births & 55 per 1,000 live births & 49 per 1,000 live births \\
$\begin{array}{l}\text { Children fully vaccinated } \\
\text { MMR (maternal mortality ratio) }\end{array}$ & $74.6 \%$ & $71.8 \%$ & $76.4 \%$ \\
$\begin{array}{l}\text { Assistance during pregnancy by } \\
\text { medically trained provider }\end{array}$ & $18.5 \%$ & 266 per 100,000 live births & 488 per 100,000 per live births \\
$\begin{array}{l}\text { Population living below the official live births } \\
\text { poverty line }\end{array}$ & $65 \%$ & $19.8 \%$ & $26.5 \%$ \\
$\begin{array}{l}\text { Household with potable drinking } \\
\text { water }\end{array}$ & $30 \%$ & $68 \%$ & $55 \%$ \\
\hline
\end{tabular}

Sources: SVRS (Sample vital registration system), 2007; CES (Centre for energy studies), 2009; DGHS (Director General of health services), 2004; BBS (Bangladesh bureau of statistics), 2007; house hold income and expenditure survey, 2005.

\subsection{The Selected Districts: Poorer Socio-Economic Profile}

The three selected districts have a much poorer socio-economic profile than the rest of Bangladesh, especially the district of Bandarban. Table 3 presents some of these key comparative figures in these districts. For example, these three districts have more than $70 \%$ of the children fully immunized (the rate varies from the high of $76.4 \%$ in Narail to $74.6 \%$ in Bandarban and $71.8 \%$ in Jamalpur). In Bangladesh as a whole it should be noted that more than $95 \%$ of children are fully immunized. However, the districts have similar IMR (infant mortality rate), U5M (under 5 mortality) and MMR (maternal mortality rate) than that of Bangladesh overall. Interestingly, Narail has far lower IMR (10.2 per 1,000 live births) than the country as a whole (65 per 1,000 live births). However, the MMR in Narail is much higher (488 per 100,000 live births) than that of Bangladesh overall (322 per 100,000 live births) [6]. On the other hand, only $18.5 \%$ of pregnant women receive assistance from medically trained personnel during delivery. For Jamalpur and Narail districts, the figures are $19.8 \%$ and $26.5 \%$, respectively. In Bangladesh as a whole more than $30 \%$ of pregnant women are assisted by medically trained personnel 
during delivery.

It is important to note that in some key social indicators the selected three districts fare much worse than the country as a whole. While in Bangladesh about $40 \%$ of the population lives below the official poverty line, in Jamalpur $68 \%$ of the population live below the official poverty line. The rates are $65 \%$ and $55 \%$ in the districts of Bandarban and Narail, respectively. At the same time, compared to $55 \%$ of the overall population in Bangladesh with access to potable drinking water, in Bandarban only $30 \%$ of the population has access to potable drinking water. The rates are $45 \%$ and $40 \%$ in Jamalpur and Narail districts, respectively.

\subsection{Health System Bottlenecks: Major Thrusts of the} Study

It is in this context that the district level health and social development officials were asked to identify health system bottlenecks in achieving the health related MDGs and to come up with credible strategies in overcoming the bottlenecks. Although the officials covered a wide range of health system issues covering most of its building blocks, major thrusts were concentrated on four building blocks of the health system-human resources for health, health care financing, governance and service delivery.

\subsection{Major Health System Bottlenecks Identified}

Bottlenecks were identified in three service categories: family oriented community based services, population oriented services, and individual oriented clinical services. Tables 4, 5 and 6 present the major bottlenecks identified by the respondents (district level health and social service officials) and strategies

Table 4 Family oriented community based services: health system bottlenecks and major suggested strategies.

\begin{tabular}{|c|c|c|}
\hline Service & Bottlenecks & Major strategies \\
\hline \multirow{8}{*}{$\begin{array}{l}\text { Family oriented } \\
\text { community based } \\
\text { services }\end{array}$} & $\begin{array}{l}\text { Inadequate number of trained HR (human } \\
\text { resource), inadequate coverage of HR }\end{array}$ & To increase the number of HR; to revise the HR policy \\
\hline & Lack of quality services & To ensure quality services \\
\hline & Unavailability of essential commodities & To ensure supply of essential commodities \\
\hline & Lack of effective awareness programs & $\begin{array}{l}\text { To provide effective awareness program; to include basic health } \\
\text { information in national school curriculum; to provide effective } \\
\text { awareness program. }\end{array}$ \\
\hline & Poor road communication & To construct new road and renovate the existing \\
\hline & $\begin{array}{l}\text { The gap in knowledge and behavioral } \\
\text { practices }\end{array}$ & $\begin{array}{l}\text { To include mass media; to provide health education at the } \\
\text { community; to provide effective BCC (behavior change } \\
\text { communication) strategies }\end{array}$ \\
\hline & Unavailability of food & Utilization the premises of the household \\
\hline & Financial barriers & To initiates strategies; to remove financial barriers \\
\hline
\end{tabular}

Table 5 Population oriented services: health system bottlenecks and strategies.

\begin{tabular}{lll}
\hline Service & Bottlenecks & Major strategies \\
\hline & Poor or no road communication & To construct new road and fix up the existing \\
& Lack of quality services & To ensure quality services \\
Lack of quality care at the facilities & $\begin{array}{l}\text { To ensure skilled health service provider and periodical } \\
\text { monitoring and supervision }\end{array}$ \\
& The unavailability of essential commodities & To ensure supply of essential commodities \\
Population oriented & $\begin{array}{l}\text { Inadequate number of human resource } \\
\text { Services }\end{array}$ & $\begin{array}{l}\text { To increase the number of HR; to revise human resource policy in } \\
\text { terms of human resource distribution and retention strategies }\end{array}$ \\
& $\begin{array}{l}\text { Effective awareness programs in population schedulable services } \\
\text { Cultural barriers (false belief/superstition), }\end{array}$ & $\begin{array}{l}\text { To involve community leaders and religious leaders in awareness } \\
\text { program }\end{array}$ \\
& $\begin{array}{l}\text { language barriers } \\
\text { Lack of motivation in the community }\end{array}$ & To provide conditioned incentives to the patrons \\
& $\begin{array}{l}\text { Lack of proper counseling skill among } \\
\text { service providers. }\end{array}$ & To develop counseling skill among the service provider
\end{tabular}


Table 6 Individual oriented clinical services: health system bottlenecks and suggested major strategies.

\begin{tabular}{|c|c|c|}
\hline Service & Bottlenecks & Major strategies \\
\hline \multirow{7}{*}{$\begin{array}{l}\text { Individual oriented } \\
\text { clinical services }\end{array}$} & Lack of essential commodity & $\begin{array}{l}\text { To ensure the supply of commodity; to provide logistic support at } \\
\text { the root level facilities }\end{array}$ \\
\hline & Poor quality of services & To ensure quality services \\
\hline & Inadequate number of human resource & To increase the number of HR \\
\hline & Lack of quality services financial barriers & To commence strategies to eliminate financial obstacle \\
\hline & $\begin{array}{l}\text { Lack of awareness among community } \\
\text { people }\end{array}$ & To provide effectual awareness program \\
\hline & Poor road communication & To construct new road and renovate the existing \\
\hline & Absenteeism of human resource & Hire and place them in their own region \\
\hline
\end{tabular}

suggested by them in each of these three service areas. In family oriented community based services, as Table 4 indicates, the five most important health system bottlenecks were: (1) inadequate number of appropriately trained human resources; (2) poor road conditions affecting access to health facilities; (3) lack of essential drugs and commodities in health care facilities; (4) the gap between peoples' knowledge on health issues and their behavioral practices; and (5) financial barriers in accessing health care services. Most of the suggested strategies quite naturally relate to these major health system bottlenecks. For example, ensuring adequate number of appropriately trained human resources in all health care facilities and ensuring the availability of essential drugs and commodities. These would require policy changes as well as behavioral changes on the part of the health professionals. Quite often absenteeism of trained health personnel (primarily physicians) is a greater problem than their numbers. On the other hand, ensuring availability of essential drugs and commodities would also require eliminating pilferage of these supplies by health facility staff.

\subsection{Innovative Strategies Suggested}

Nevertheless, a number of interesting and highly valuable strategies were suggested by the respondents. These include further strengthening the health awareness program, promoting early and complete breastfeeding, using the mass media to promote health education at the community level, introducing basic health and hygiene information in the school curriculum, incorporating sanitation and hygiene education sessions within the EPI (Extended Program of Immunization), and actively involving community and religious leaders in all aspects of health education and awareness programs. Some of these strategies would require long-term commitment on the part of the public policy makers as well as good governance at all levels. Clearly, the respondents were quite enthusiastic in coming up with innovative ideas and strategies in addressing the health system bottlenecks.

In identifying health systems bottlenecks in terms of population oriented services (Table 5), the respondents were more introspective and bolder in critically looking at their own shortcomings and system issues. For example, along with identifying shortage of trained human resources as a major health system bottleneck, the respondents also talked about "lack of quality care" at health care facilities as a major system issue. Clearly, they were critical of their own performance as a major problem. Moreover, they identified cultural barriers (such as peoples' belief in superstitions affecting their health seeking behavior) as well as language barriers (the difference between the spoken language of health service providers and that of the clients creating communication difficulties) as bottlenecks. The respondents were also critical of their poor counseling skills as a system bottleneck. On the other hand, in this case too non-availability of essential drugs and commodities (especially family planning supplies) was identified as a major health system bottleneck.

For population oriented services, a number of interesting and innovative strategies were suggested to 

Goals: Major Findings from District Level in Bangladesh

overcome the health system bottlenecks. These include greater budget allocation for the health sector, introducing demand side financing to encourage greater utilization of health care services by clients (in encouraging institutional delivery such a demand side financing could be an effective strategy), counseling for caretakers on administration of antibiotics at home, and ensuring availability of commodities/family planning supplies.

Moreover, a number of strategies were suggested to aim at improving the efficiency of all levels of health care workers. These include increasing the number of trained human resources at the facility level so that they can better cover all types of service provision and, at the same time, greater training for $\mathrm{HRH}$.

A number of broader policy issues were also raised. For example, how to ensure more equitable distribution of human resources for health across the urban-rural divide? How to ensure retention of such human resources? Strengthening public-private partnership was also raised as a policy issue. At the same time, extending EPI coverage to hard-to-reach areas, increasing the number of satellite clinics to reach people in remote areas, improving antenatal care services, and removing financial barriers in accessing health care services (for example, eliminating user fees, reducing transportation costs, etc.) were innovative policy ideas that were presented by the respondents.

For Individual-oriented clinical services (Table 6), most of the health system bottlenecks relate to human resources for health-their scarcity, quality and absenteeism. Poor road condition was also noted as a bottleneck. On the other hand, major strategies suggested were primarily concentrated on the nature and quality of different types of clinical services. For example, increasing the number of facilities: (1) equipped with providing emergency obstetric services; (2) tuberculosis detection; (3) pneumonia treatment; and (4) antenatal and post-natal care.

Other strategies noted include ensuring the supply of oxytocin in all health facilities, launching intensive community based health education and health awareness programs, improving the supervision, monitoring and the accountability of the health care system, incorporating basic health and hygiene information in school curricula, and further strengthening the growth monitoring, counseling and supplementary food program. It is important to note that at this level (individual oriented clinical services) the respondents were very concerned about the accountability of the health system and emphasized the need for strengthening supervision and monitoring services. Clearly, the onus was on strengthening the overall governance of the health system and ensuring quality of health care services.

\section{Discussion}

Early breast feeding was used as a proxy for family oriented preventive services. Most of the pregnant women did not visit any health facility for three ANC (antenatal care) services where they could receive appropriate knowledge and training on breastfeeding. Not surprisingly, neither the practice of exclusive breastfeeding nor that of the onset of breast feeding within one hour of birth is common among new mothers. Only $46.0 \%$ children $<6$ months are exclusively breast feed [7]. Inadequate coverage of human resources at the grass root level was identified as a bottleneck that discourages women to seek health care from facilities. In addition, community people do not understand the importance of ANC and, as a result, they do not prefer to visit facilities that demands laborious journey considering the poor road transportation system. Children miss the opportunity to receive exclusive breastfeeding because mothers and the families do not fully comprehend the importance of exclusive breastfeeding. Moreover, most of the mothers do not get a friendly environment at home or at the health facilities in terms of time and privacy required for breastfeeding. Enhancing the BCC skills of community-based health workers and further improving the quality of ANC services could be 
extremely useful in overcoming these bottlenecks.

\subsection{Sanitation and Hygiene Issues}

Lack of proper sanitation is also raised as an important health issue. Only 33\% population has unshared sanitary latrine facility at their household [8]. However, scarcity of water at the hilly district could also be an important factor in this respect. On the other hand, only $16.8 \%$ of the population practice safe disposal of child feces. Several strategies had been proposed to further strengthen the community-based awareness program in order to address these sanitation and hygiene related issues. It was noted that population visited by CHW (community health worker); HA (health assistance)/FWA (family welfare assistance); under three most critical interventions-use of sanitary latrine, complementary feeding, and ORT (oral rehydration therapy)-are 45\%, 65\% and 65\%, respectively. Since it is a hill area, the distances across the villages are demanding in terms of time and physical effort. Nevertheless, a health worker is required to cover five to six villages with a combined population of 5,000 to 6,000 . Clearly, more community-based health workers are required to effectively cover sanitation and hygiene issues at the grass-root level.

\subsection{Continued Food Insecurity}

According to BBS (Bangladesh Bureau of Statistics) 2010 household survey, poverty which stood at $40.4 \%$ in 2005 moved down to $31.5 \%$ in 2010 . However, malnutrition and micronutrient deficiency among children and women (especially pregnant women) remain high, suggesting a high level of food insecurity. The participants proposed the promotion of "kitchen gardening” at the community level to improve food security. Inadequate coverage of community-based basic health services was identified as a critical issue. It was reported that only $45 \%$ of the population are covered by community health workers providing basic health services including complementary feeding. At the community level, only $6 \%$ of diarrhea cases are treated with zinc. Inadequate training of service providers on diarrhea management protocol and unavailability of zinc at health facilities were cited as bottlenecks in this regard. In order to overcome these bottlenecks it is essential to ensure the availability of commodities like basic sanitary materials (ring, slab, etc.) to the poor at an affordable cost (or at free of cost for the ultra poor), supplementary food for lactating mothers, and supply of zinc at all of the facilities. These measures, it is argued, would further strengthen the family oriented community services. Free services for the poor were proposed to overcome existing financial barriers for the individual oriented clinical services. Further enhancing the community based health education and awareness programs was identified as critical in promoting institutional deliveries, proper utilization of ANC and PNC (post natal care) services and in developing a positive health seeking behavior regarding children pneumonia at the community level. The participants also noted the importance of launching a mass awareness program at the community level on the danger signs of pneumonia.

\subsection{Scarcity of Skilled Birth Attendants}

At the community level, the number of FWVs (family welfare visitors) and CSBAs (community-based skilled birth attendants) were found to be inadequate. It was felt that at least two skilled teams are needed to provide quality services in two shifts at the FWCs. Local recruitment of FWVs had been proposed to make the services culture sensitive. In order to ensure quality service, refresher training for CSBAs and their proper monitoring and supervision by the health facility higher-ups, home visits by health care providers (especially after delivery), appropriate training like IMCI (integrated management of childhood illness) training for FWVs and SACMO (sub assistant community medical officers), clinical training for SACMO, refresher training and further capacity building of field level workers on BCC had 
been proposed. At the same time, yearly intake of CSBA trainees in nursing schools should substantially increased to meet the need at the community level.

\subsection{Poor Infrastructure of Health Facilities}

Poor infrastructure of most of the health facilities was also identified as a bottleneck in ensuring quality services. Improvement of the infrastructure including functioning X-ray machines, proper laboratory equipment for TB (tuberculosis) tests and tests for other common diseases, appropriate facilities for normal delivery, and facility-based treatment of children pneumonia were identified as critical requirements in resolving these bottlenecks. It was also noted that selected number of Upazila health complexes (for example, one in every four) should be fully equipped with handling complex delivery cases including C-section (cesarean section).

\section{Conclusions}

Inadequate number of appropriately trained human resources for health and their lopsided distribution across the urban-rural divide, poor transportation system, poor physical infrastructure of health care facilities, lack of drugs and other commodities and lack of awareness on basic health and hygiene among the population at large were some of the common bottlenecks identified by the study. The study, therefore, stressed the need for improving the infrastructure of health facilities at all levels, enhancing the skills of community-based health workers through training and refresher courses, and launching massive community level awareness programs along with effective behavioral change and communication strategies as critical for ensuring quality services. Systemic constraints in implementing such changes must be identified and resolved. In this respect, priority must be given to maternal, newborn and child health services. It is argued that quality-public health services must be made available to all segments of the population and that equity must remain the fundamental policy guiding the entire health system. Inclusive service provision is essential to attain the fundamental goals set by the health system as well as the Millennium Development Goals.

\section{Acknowledgment}

The authors gratefully acknowledge the financial support received from UNICEF, Bangladesh in 2010 for carrying out the study.

\section{References}

[1] Lalji, N., Thaver, A. M., and Kamal, A. 2010. "Maternal Neonate and Child Health (MNCH) Research in Pakistan: Trend and Transition." Jounal of Pakistan Medical Association 60 (5): 401-3.

[2] United Nations Children's Fund. 2009. Situation Assesment and Analysis of Children and Women in Bangladesh. Dhaka: United Nations Children's Fund, 84.

[3] Bergeson, J., Lockwood, E., Madsen, L., and Bernstein, J. 2001. Maternal Health Supplies in Bangladesh. Washington, DC: Population Action International, 12.

[4] Jimenez Soto, E., La Vincente, S., Clark, A., Firth, S., Morgan, A., and Dettrick, Z. 2013. "Investment Case for Improving Maternal and Child Health: Results from Four Countries.” BMC Public Health 13 (601): 1-14.

[5] Arifeen, S. E., Christou, A., Reichenbach, L., Osman, F. A., Azad, K., and Islam, K. S. 2013. "Community-Based Approaches and Partnerships: Innovations in Health-Service Delivery in Bangladesh.” Lancet 382 (9909): 2012-26.

[6] Bangladesh Bureau of Statistics. 2011. Sample Vital Registration System Bangladesh. Dhaka: Bangladesh Bureau of Statistics, 5.

[7] Bangladesh Bureau of Statistics. 2008. Bangladesh Statistical Pocket Book. Dhaka: Bangladesh Bureau of Statistics.

[8] Rahman, M. 2009. Sanitation Sector Status and Gap Analysis: Bangladesh. Dhaka: Global Sanitation Fund, Water Supply and Sanitation Collaborative Council. 

Goals: Major Findings from District Level in Bangladesh

Appendix 1: Geographical location of the study districts

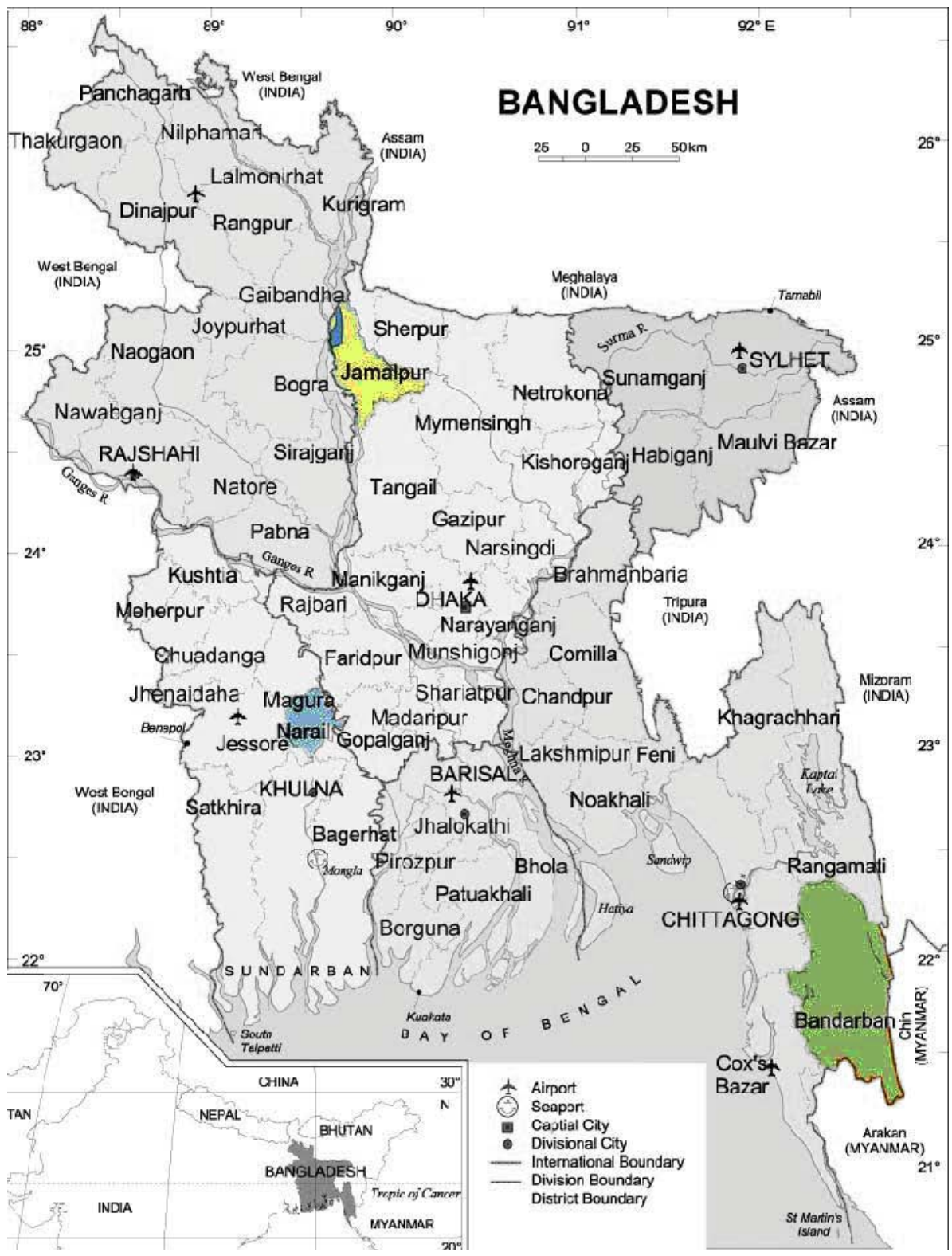

Bandarban:

Bandarban District (Chittagong division) with an area of $4479 \mathrm{sq} \mathrm{km}$, and a population of 340,701. The district lies in a hilly area closer to the border with Myanmar. Bandarban mostly consists of forests and hills.

Jamalpur :

Jamalpur District (Dhaka division) with an area of $2031.98 \mathrm{sq} \mathrm{km}$ and a population of 2.4 million. It is closer to the Meghalaya State of India in the north and home to a few small manufacturing plans.

Narai:

Narail District (Khulna division) has a population of almost 760,000 and an area of $990.23 \mathrm{sq} \mathrm{km}$. It is in a deltaic area in south-western Bangladesh. 